\title{
U.S. DEPARTMENT OF ENERGY QUARTERLY TECHNICAL PROGRESS REPORT
}

Project Title: IEMDC -In-Line Electric Motor Driven Compressor

Report Type: Quarterly

Reporting Period: Start Date: January 01, 2004

End Date: March 31, 2004

Principal Author(s): Michael J. Crowley (DR),

Prem N. Bansal (EMD),

Report Issue Date: April 2004

Award Number: DE-FC26-02NT41643

Recipient: Dresser-Rand Company

(Submitting Organization) P.O. Box 560

North $5^{\text {th }}$ Street

Olean, NY 14760-2322

Subcontractors: Curtiss-Wright Electro-Mechanical Corporation (EMD) 1000 Cheswick Avenue

Cheswick, PA 15024 
Quarterly Progress Report - 5th Quarter

Date: April 2004

DE-FC26-02NT41643

\section{Revision Page}

$\begin{array}{ccccc}\text { Revision } & \text { Revised By } & \begin{array}{c}\text { Date } \\ \text { April 2004 }\end{array} & \text { Initial Issue } & \text { Remarks } \\ 00 & --- & \text { Apris } & \end{array}$




\section{** DISCLAIMER **}

"This report was prepared as an account of work sponsored by an agency of the United States Government. Neither the United States Government nor any agency thereof, nor any of their employees, makes any warranty, express or implied, or assumes any legal liability or responsibility for the accuracy, completeness, or usefulness of any information, apparatus, product, or process disclosed, or represents that its use would not infringe privately owned rights. Reference herein to any specific commercial product, process, or service by trade name, trademark, manufacturer, or otherwise does not necessarily constitute or imply its endorsement, recommendation, or favoring by the United States Government or any agency thereof. The views and opinions of authors expressed herein do not necessarily state or reflect those of the United States Government or any agency thereof." 


\begin{abstract}
This report covers the fifth quarter (01/01/04 to 03/31/04) of the In-Line Electric Motor Driven Compressor (IEMDC) project. Design efforts on the IEMDC continued with compressor efforts focused on performing aerodynamic analyses. Theses analysis were conducted using computational fluid dynamics.

Compressor efforts also entailed developing mechanical designs of components through the use of solid models and working on project deliverables. Electric motor efforts focused on the design of the magnetic bearing system, motor pressure housing, and the motor-compressor interface. The mechanical evaluation of the main interface from both the perspective of the compressor manufacturer and electric motor manufacturer indicates that an acceptable design has been achieved. All mechanical and aerodynamic design efforts have resulted in considerable progress being made towards the completion of the compressor and electric motor design and towards the successful completion of the IEMDC unit.
\end{abstract}


Table of Contents

Title Page

Page

Revision Page

Abstract

Table of Contents

Introduction

Executive Summary

Experimental

Results and Discussion

Conclusion

References

List of Acronyms and Abbreviations

\section{List of Graphical Materials}

No.

Figures

Page

1 Conceptual Unit

2 Compressor Section Internal Components 12

3 Inlet Configuration 12

$4 \quad$ Inlet Streamline Plot 13

$5 \quad$ Inlet Vector Plot near the Hub 13

$6 \quad$ Inlet Vector Plot at Midspan 14

7 Inlet Vector Plot near the Shroud 14

8 Inlet Vector Plot near the Symmetry Plane 15

9 Total Pressure Loss Coefficient at the Impeller Eye 16

10 Inlet Normalized Mass Flow Distribution 16

11 Inlet Normalized Pressure Distribution 17

12 Inlet Normalized Total Pressure Distribution 17

13 Inlet Meridional Velocity Distribution 18

14 Inlet Absolute Tangential Velocity Distribution 18

15 Inlet Absolute Flow Angle Distribution 19

16 Inlet Standard Deviation of Absolute Flow Angle 19

17 IEMDC Compressor Stage Geometry 20

18 Vaneless Diffuser Computational Mesh 21

19 Vaned Diffuser Computational Mesh $\quad 21$

20 Compressor volute Computational Mesh 22

$21 \quad$ Pie Slice Impeller Mesh with Inlet Extension 22 
Quarterly Progress Report - 5th Quarter

Date: April 2004

DE-FC26-02NT41643

\section{List of Graphical Materials (cont'd)}

No.

Figures

Page

22 Inlet Computational Mesh

23

23 Inlet Guide Vane Computational Mesh

23

24 Full $360^{\circ}$ Impeller Mesh with Secondary Passages

24

25 Complete Flowpath Streamline Plo

24

26 Flowpath Stage Pressure Rise Plo

25

27 Non-axisymmetric loads on Impeller Surface

25

No.

$\underline{\text { Tables }}$

Page

1 Prototype Operating Performance Point 


\section{Introduction}

The In-line Electric Motor Driven Compressor (IEMDC) project is the development of an integrated electric motor driven compressor to address the needs of the Natural Gas Industry. It represents a revolutionary advance in compressor system design and performance, in an improved package.

The objective of the project is to develop the design of a direct coupled, seal-less, In-Line Electric Motor Driven Compressor to the point where detailed manufacturing drawings may be started. This gas compressor will utilize a variable speed induction motor with magnetic bearings that is integrated with a single-stage overhung centrifugal compressor. It will be an electrically powered, highly flexible, efficient, low maintenance compressor that can be quickly ramped up to meet peak demands. The unit design proposes to provide low cost, low maintenance gas compression for the Natural Gas Industry while minimizing the environmental, regulatory, and maintenance issues associated with gas fired drives by the use of an electric motor as the prime mover. 


\section{Executive Summary}

\section{Unit Configuration and Integration}

The design and development process of mechanically integrating the compressor and motor gained significant progress during this quarter. Efforts during the design of the electric motor section of the IEMDC included an evaluation of the motor-compressor interface. An interface design was developed during the fourth quarter of the project and evaluated from the standpoint of the compressor during the design of the compressor casing. Subsequently during the fifth quarter, the interface design was evaluated from the standpoint of the electric motor during the design of the motor casing. This completes the independent evaluation from both the electric motor and compressor manufacturer. The results are in agreement that the evaluations indicate that the design is satisfactory to meet appropriate requirements and standards. This is a significant step in validating the feasibility of the mechanical design integrity of the unit.

Progress has continued towards the development of the control and instrumentation design for the IEMDC unit. As the details are developed greater definition of the system auxiliary systems can be prepared to develop cost for the unit and unit installation. Also, the control interactions between the magnetic bearing control system, cooling gas conditioning skid, unit control panel, and variable frequency drive can be considered.

Additionally, a five-page technology assessment report was submitted for approval. This report discusses the state-of-the-art technology being developed on the project as well as competing technologies. A technology assessment report is a deliverable of the award.

\section{Compressor Design}

Mechanical design efforts focused on the unit layout and assembly of the compressor components in the fifth quarter. Details and interfaces of internal components were reviewed in the context of assembly so that thorough and proper design considerations can be made. The functionality of component parts, sequence of assembly, and potential field service requirements must be considered during the design phase.

Aerodynamics for the compressor focused on performing computational fluid dynamics analysis (CFD) on the final flowpath components of the prototype unit. An analysis was completed on the final inlet configuration for the unit. This analysis showed reduced distortion and improved uniformity of the flow over the previous designs. Several types of CFD analyses are in the process of being performed on the final flowpath configuration. These analyses consist of pie-slice models and three hundred and sixtydegree aerodynamic models using both vaned and vaneless diffuser configurations. Pie-slice models were modeled and completed near the end of the first quarter. More steady state analysis with comprehensive three hundred and sixty-degree aerodynamic models that include secondary flow passages are currently in progress.

\section{Electric Motor}

Significant progress was made toward completing the design of critical motor components. Considerable progress was made on the design of the magnetic bearing system, the motor pressurized housing, and the motor-compressor interface flange. Kingsbury Magnetic Bearings carried out the design and analysis of the magnetic bearing system under a contract with EMD. Reports on the magnetic bearing system design will be prepared during the next quarter. FEA models of the motor rotating and static structures were developed to verify the predictions of the bearing manufacturer's design as well as to perform further in depth analyses to investigate the effect of the foundation flexibility on motor vibrations. Considerable design effort was also expended in evaluating the motor-compressor interface flange and the motor pressure vessel designs. It was determined that both designs meet or exceed appropriate requirements of the ASME and API 617 design codes. The report is presented in Appendix A. 
Several sessions of a design review meeting were held to discuss these topics with Kingsbury/S2M, Curtiss-Wright EMD, and Dresser-Rand Company in attendance. All three manufacturers participated in the review of the magnetic bearing system. A separate review session was held with Curtiss-Wright EMD and Dresser-Rand Company to discuss the progress and work that was performed on the motor pressurized housing and the motor-compressor interface flange.

An extensive literature search was performed to collect, review, and to evaluate the effect of the constituents of the "sweet gas" on the motor insulation. The gas constituents are described in various gas pipeline tariffs and were also obtained from a potential IEMDC end user. The preliminary findings are that no adverse impact on the motor insulation life is anticipated and the results of the literature search will be summarized in a report during next quarter.

The stator half coil design is underway and is planned for completion by the end of May. Considerable effort is being expended to research the applicable electrical and design safety codes for the motor power junction boxes. Preparation of design specification for the pressure boundary terminal glands is progressing on schedule. Further work was continued on updating the motor outline, layout, and motorcompressor interface drawings. The completion of the DOE deliverables is continuing to be on schedule.

Thus, the design iterations of the last five quarters continue to confirm the feasibility of an efficient and robust motor design for the $10 \mathrm{MW} 12,000 \mathrm{rpm}$ variable speed motor. 
Quarterly Progress Report - 5th Quarter

Date: April 2004

DE-FC26-02NT41643

\section{Experimental}

No experimental work was performed during this reporting period. 


\section{Results and Discussion}

\section{Unit Configuration and Integration}

Packaging work was started for the gas conditioning system for the IEMDC unit. The gas conditioning system is an auxiliary system that will regulate the pressure of the discharge gas that is used to provide ventilation for the motor. This system will also filter out undesirable particulate matter from the gas flowing to the motor. Preliminary work performed on this system includes reviewing the major components such as filter and valve options. Currently a preliminary filter has been selected and several valve options are being considered for the cooling gas control set-up. Information from the filter and valves being reviewed in addition to the information being developed on the control interfaces of the system will be used to further the development of instrumentation and control diagrams for the IEMDC system.

\section{Compressor Design}

\section{Component Design and Unit Assembly}

The assembly of the compressor section internal components and interface with the electric motor were given considerable attention in this quarter. A significant amount of time was spent building prototype solid models of the compressor internals and components that interfaced with the electric motor. Figure 1 shows the most recent conceptual model of the unit without any motor mounting attachments. This shows the final case design concept for the compressor section of the unit.

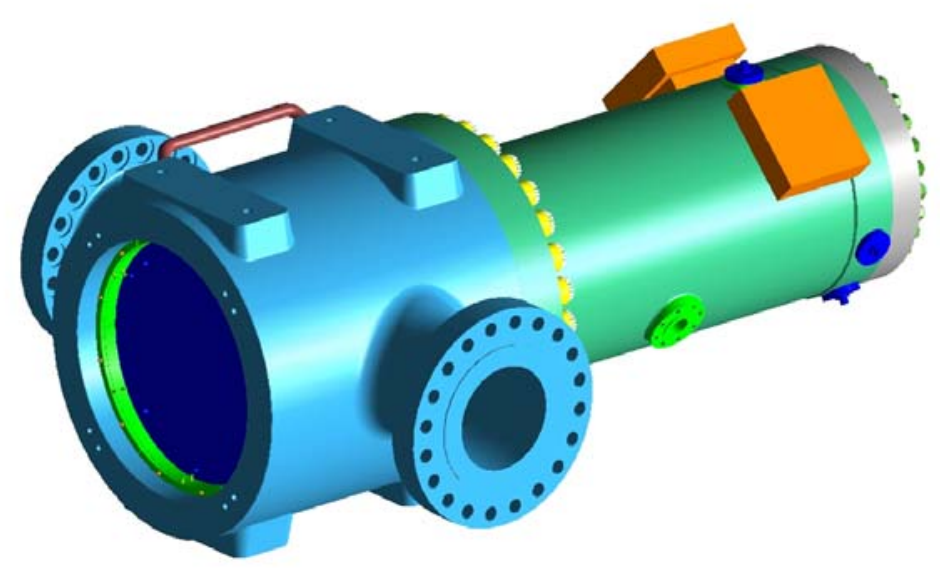

Figure 1: Conceptual unit design with detailed compressor case.

Figure 2 shows a cross-section removed from the compressor module to expose the internal components. This solid model assembly was used to review and develop component interface requirements. Additionally, solid model assemblies will aid in reviewing unit assembly procedures during manufacture. This will ensure that appropriate manufacturing considerations are made during the design phase. Examples of considerations that can be determined from solid model assemblies are the tooling required for removing the bundle and internal parts from the unit.

Solid models of components also assist in obtaining cost estimates from vendors. Parasolids can be transmitted to vendors to more accurately portray the component resulting in a more accurate cost estimate. Compressor case parasolids and volute parasolids were transmitted to vendors to obtain cost estimates of these components. Some detail work is still required to complete the final component designs, however, interface connections between components, space allocations, flowpath surfaces, and part functionality have been determined. Any remaining detail work will be completed in the next phase when manufacturing drawings are created. 


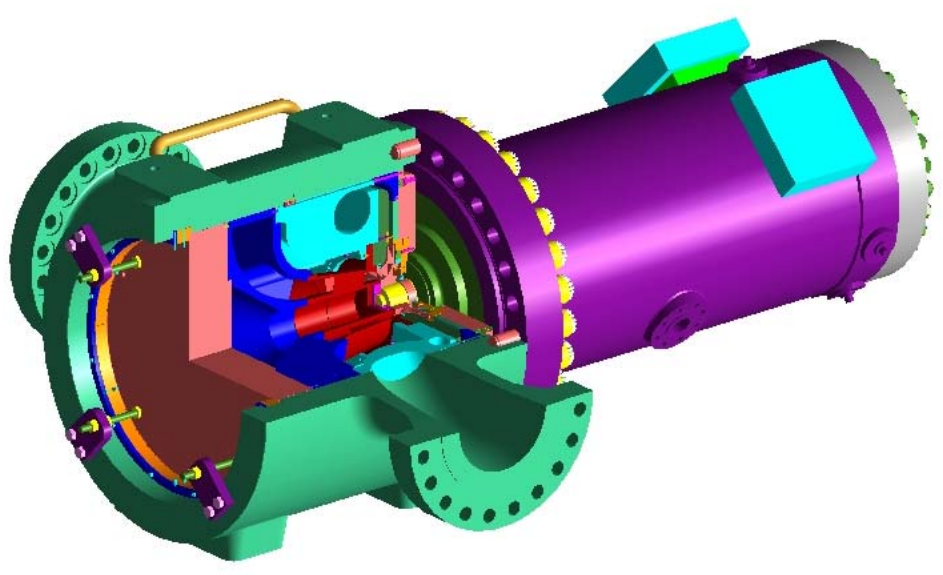

Figure 2: View of compressor section internal components.

\section{Inlet Design and Analysis}

An aerodynamic analysis was completed on the final compressor inlet configuration. This inlet is designated as inlet number three (3) and contains a combination of features that were analyzed in the first two inlet configurations. Inlet number three incorporates the inlet plenum region of the first inlet configuration and the vane designs of the second inlet configuration. In addition, a modified inlet configuration was added to the new inlet configuration as shown in Figure 3. As seen in Figure 3, the design of the geometry opposite the nozzle will provide improved area transition and better turning of the flow into the bottom inlet guide vanes. The new inlet design was evaluated at three different mass flow rates to determine the effect of various operating flow conditions.

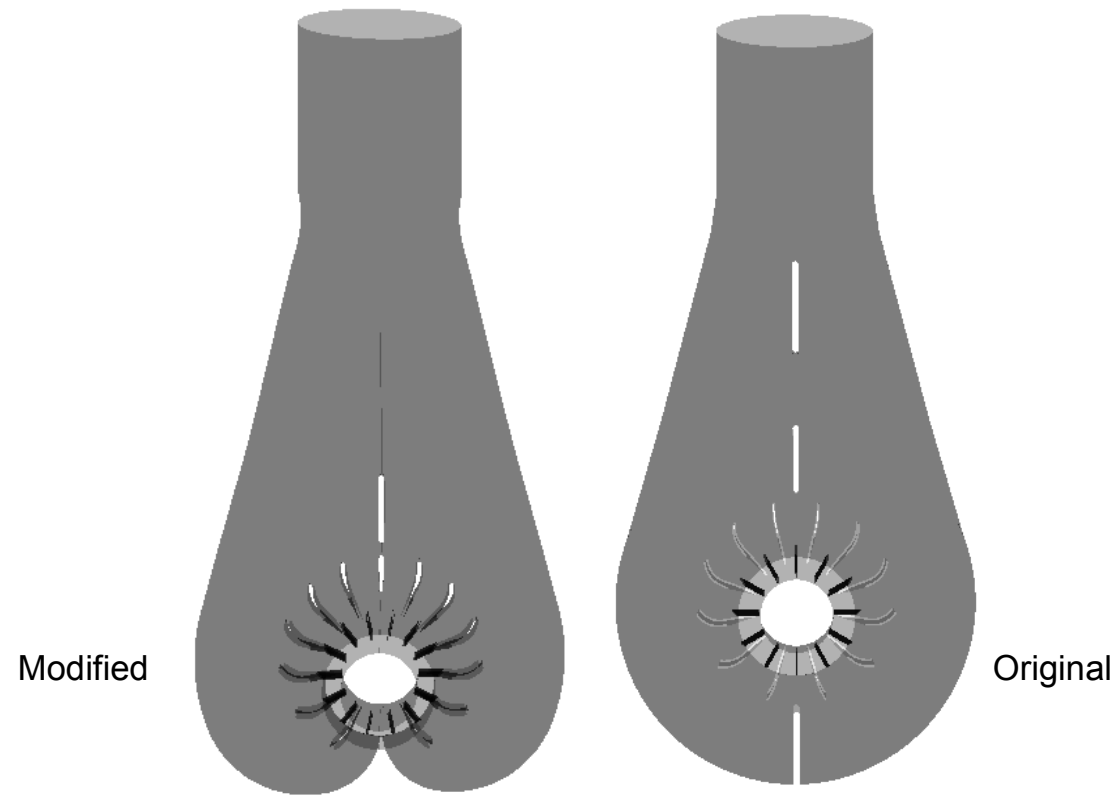

Figure 3: Inlet configuration w/ geometry modifications.

Figures 4 through 8 show the flow profiles for the different mass flow rates analyzed in the third inlet model configuration. The streamline and vector plots at the different locations indicate that the seagull configuration and the inlet vanes guide the flow in a uniform pattern. No flow separation or adverse incidence effects are indicated in these plots at the leading edges of the vanes. 


\section{DE-FC26-02NT41643}
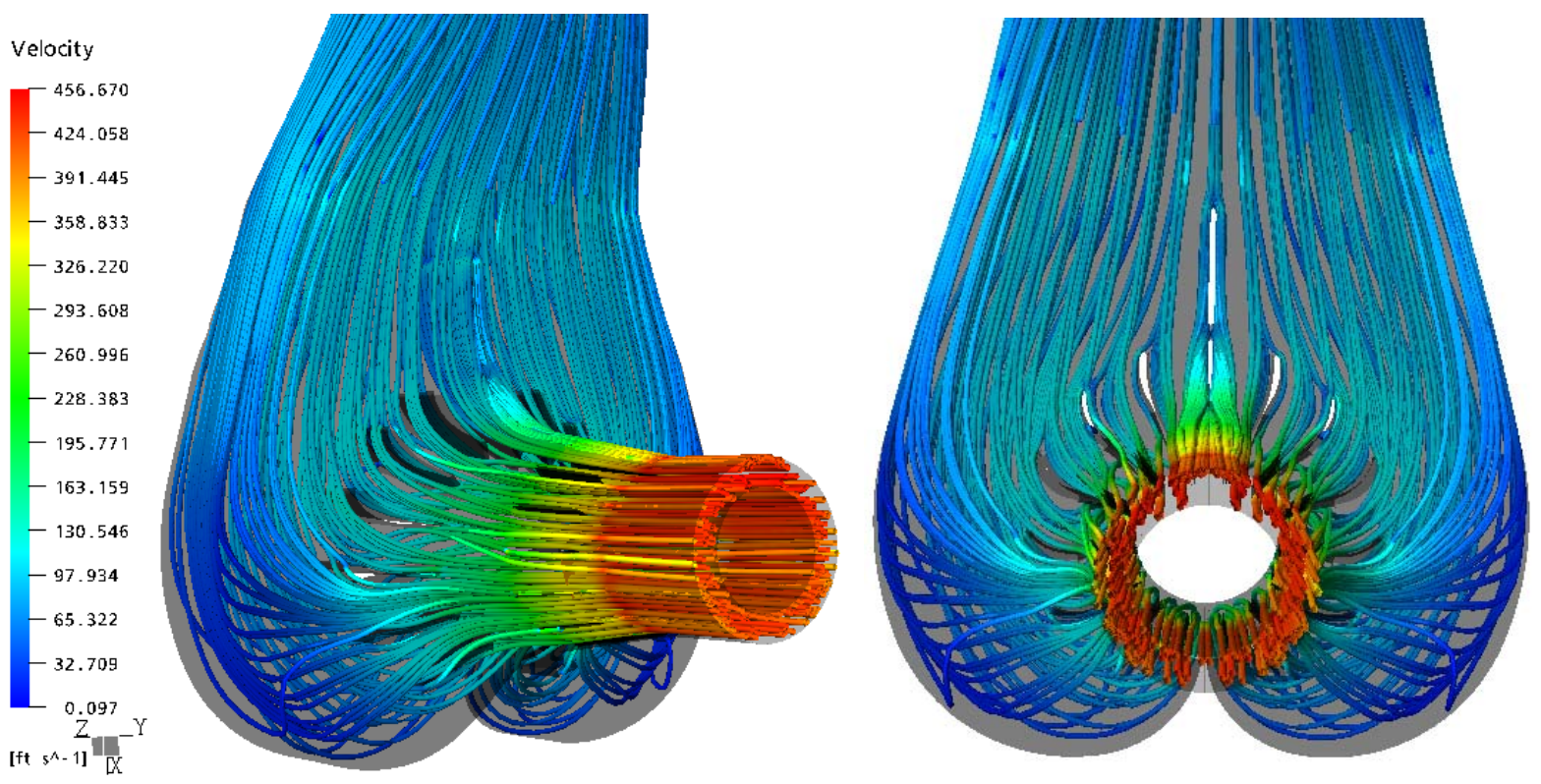

Figure 4. Streamline of radial inlet $3 @$ exit Mach number 0.286 (front and side view)
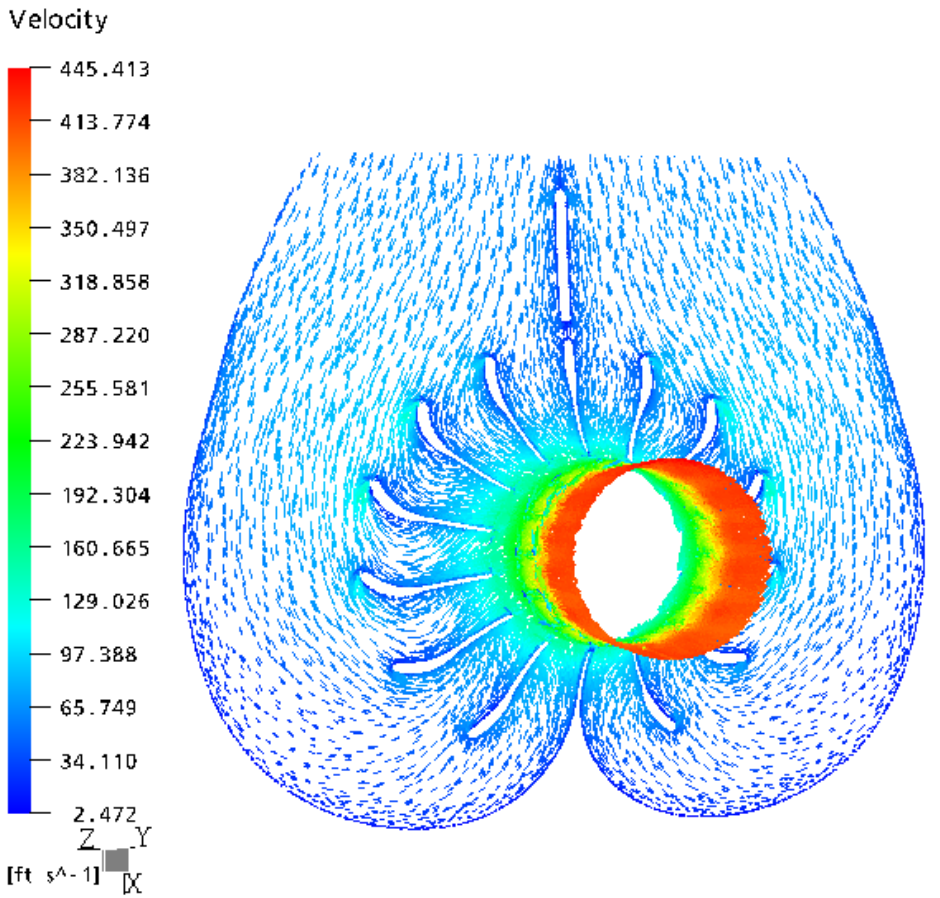

Figure 5. Vector plot of radial inlet 3 near hub with exit Mach number 0.286 

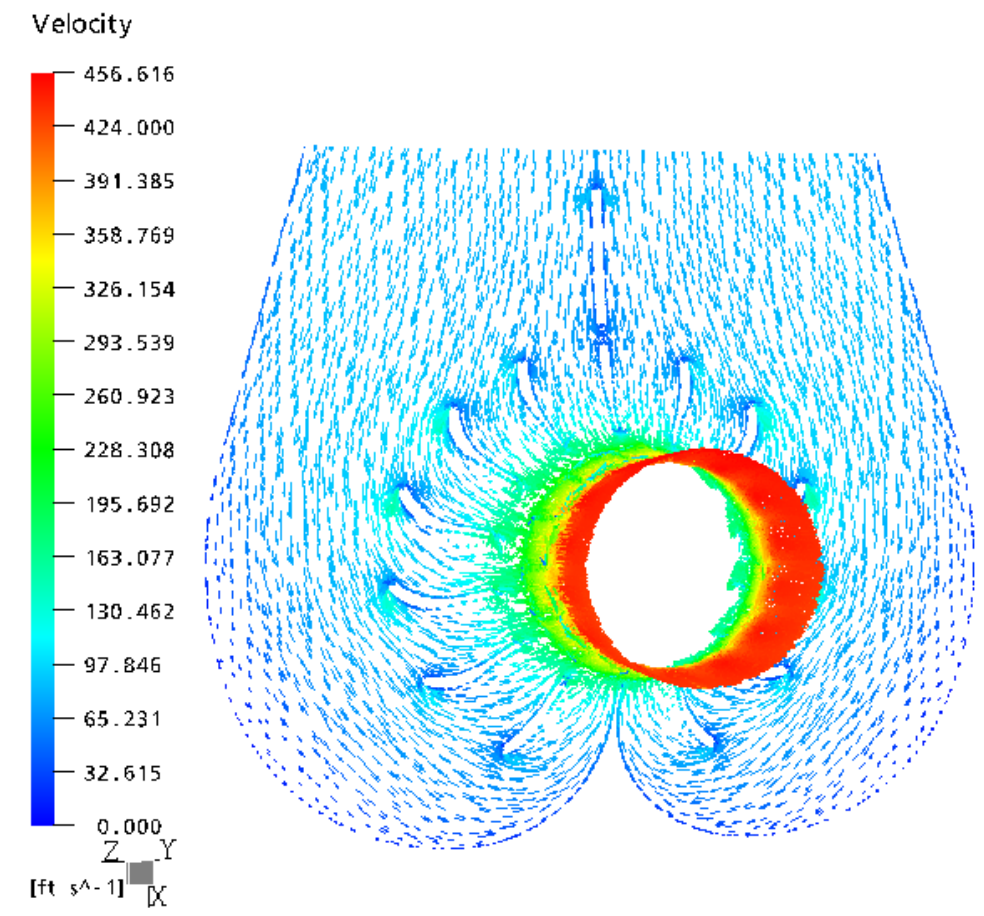

Figure 6. Vector plot of radial inlet 3 at midspan with exit Mach number 0.286 velocity
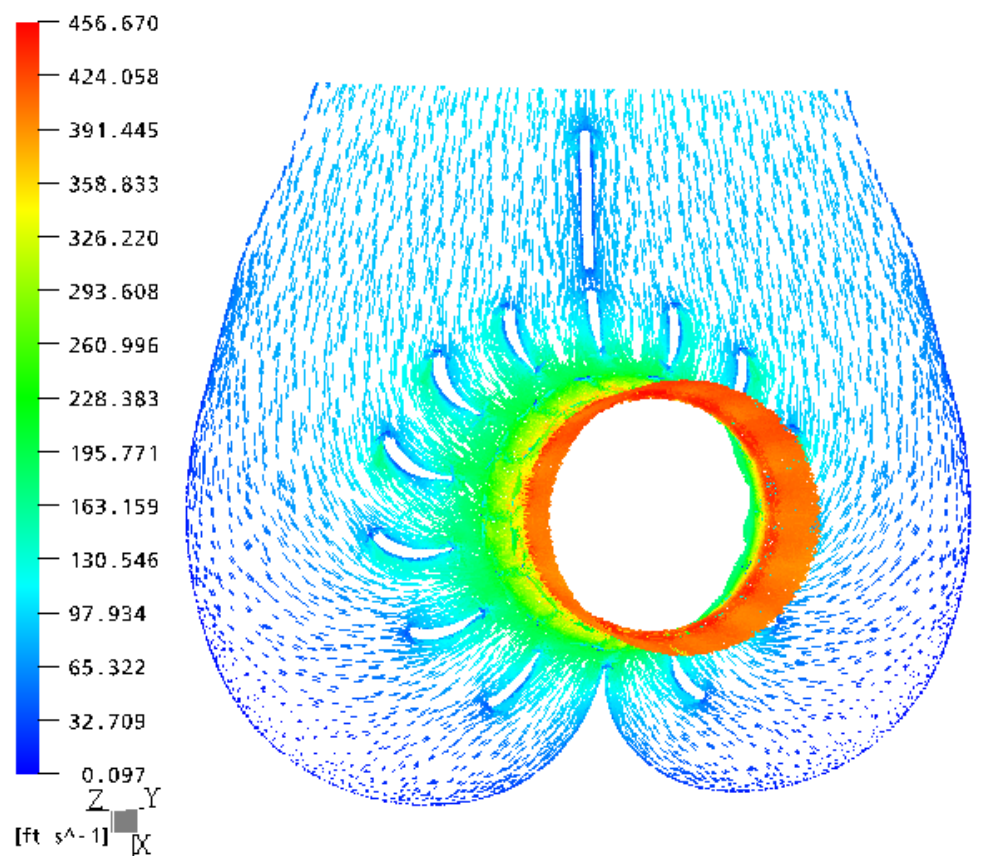

Figure 7. Vector plot of radial inlet 3 near shroud with exit Mach number 0.286 

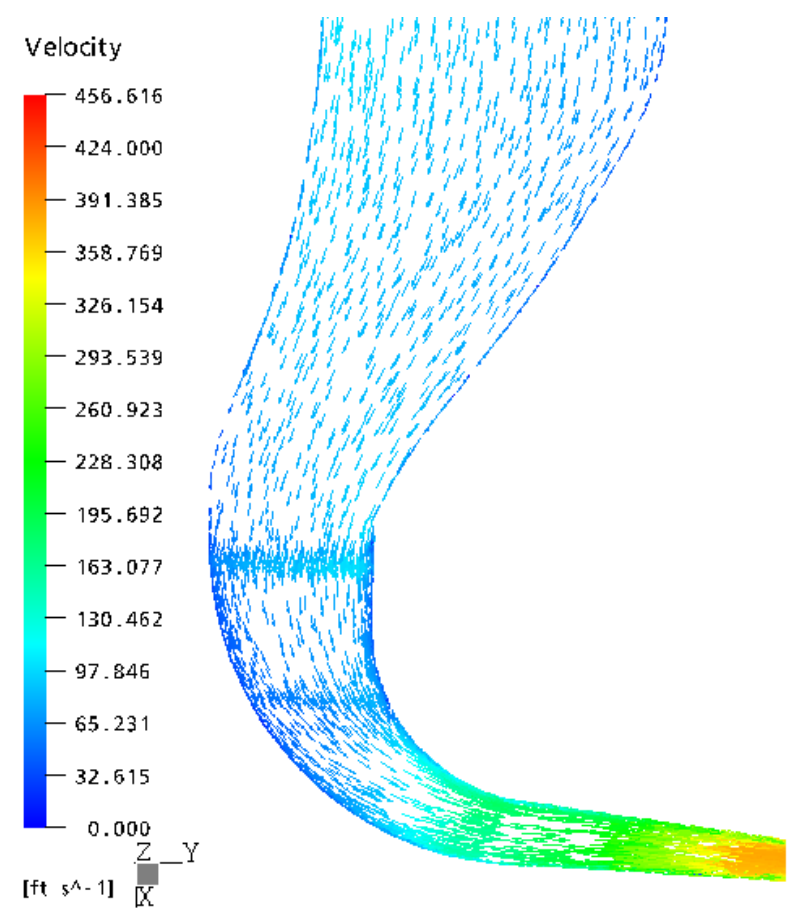

Figure 8. Vector plot of radial inlet 3 near symmetry plane with exit Mach number 0.286

Figures 9 through 16 show the quantitative performance comparison of the different inlet models. Aerodynamic performance parameters such as total pressure loss, mass flow distribution, pressure, and total pressure at the IGV exit are shown in these figures between the inlet flange and inlet exit (impeller eye). These figures show comparisons between the final inlet configuration and the two previous inlet configurations previously analyzed.

Normalized mass flow distribution within the IGV passages at various Mach numbers at the inlet exit are shown in Figure 10. Notice that the distribution is within approximately $1 \%$ regardless of the exit Mach number as referenced to the averaged value. A comparison of normalized static and total pressure plots is made in figures 11 and 12 for the three inlet configurations. These results also show variation within $1 \%$ of the averaged quantities.

A comparison of tangential velocity distribution at the IGV exit for three different exit Mach numbers is shown in Figure 14. Note that the tangential velocities for the third inlet design were reduced in magnitude. In addition, the new design is less sensitive to the various exit Mach numbers when compared to the first and the second inlet models. Consequently, as shown in figure 15, the flow angle has been improved with the third design indicating less flow distortion at the following impeller eye.

Figure 16 shows the comparison of the standard deviation of flow angle over the expected range of exit Mach numbers. The standard deviation of flow angle is the measure of uniformity of the flow direction. The flow uniformity of the third inlet design is less sensitive over a wide range and improved from the second inlet design. 


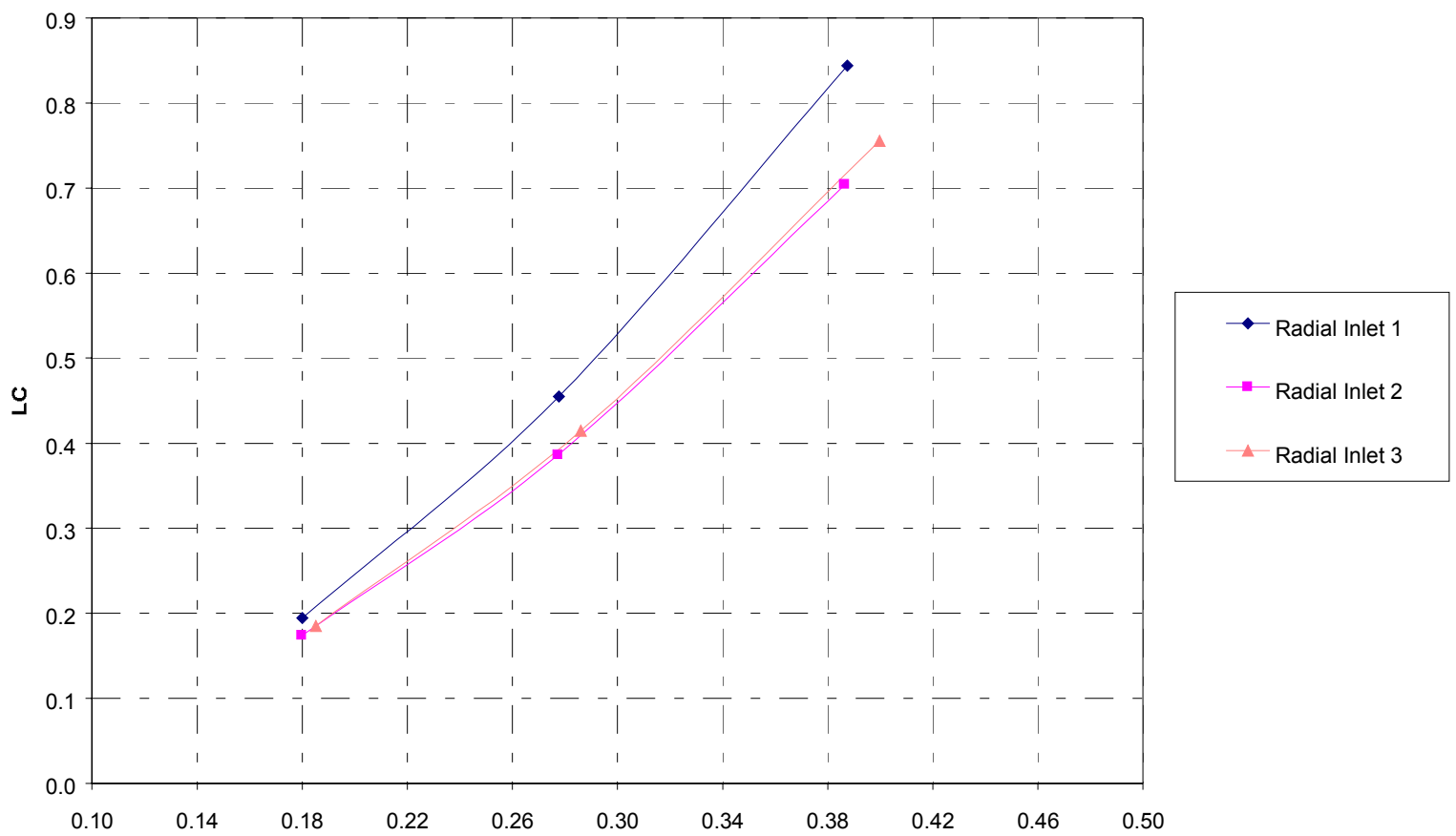

Figure 9. Total pressure loss coefficient at impeller eye

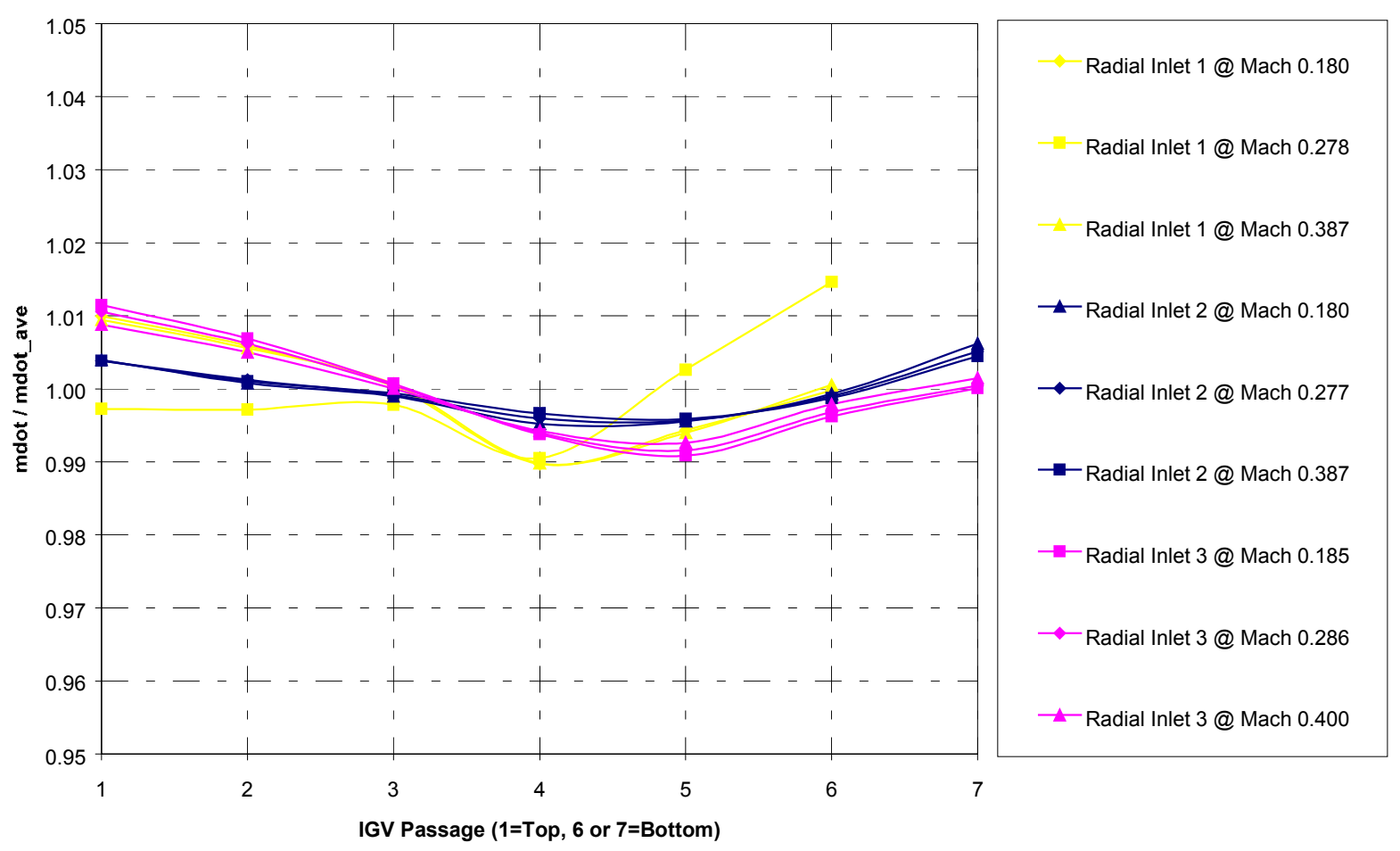

Figure 10. Normalized mass flow distribution @ various exit Mach no. 

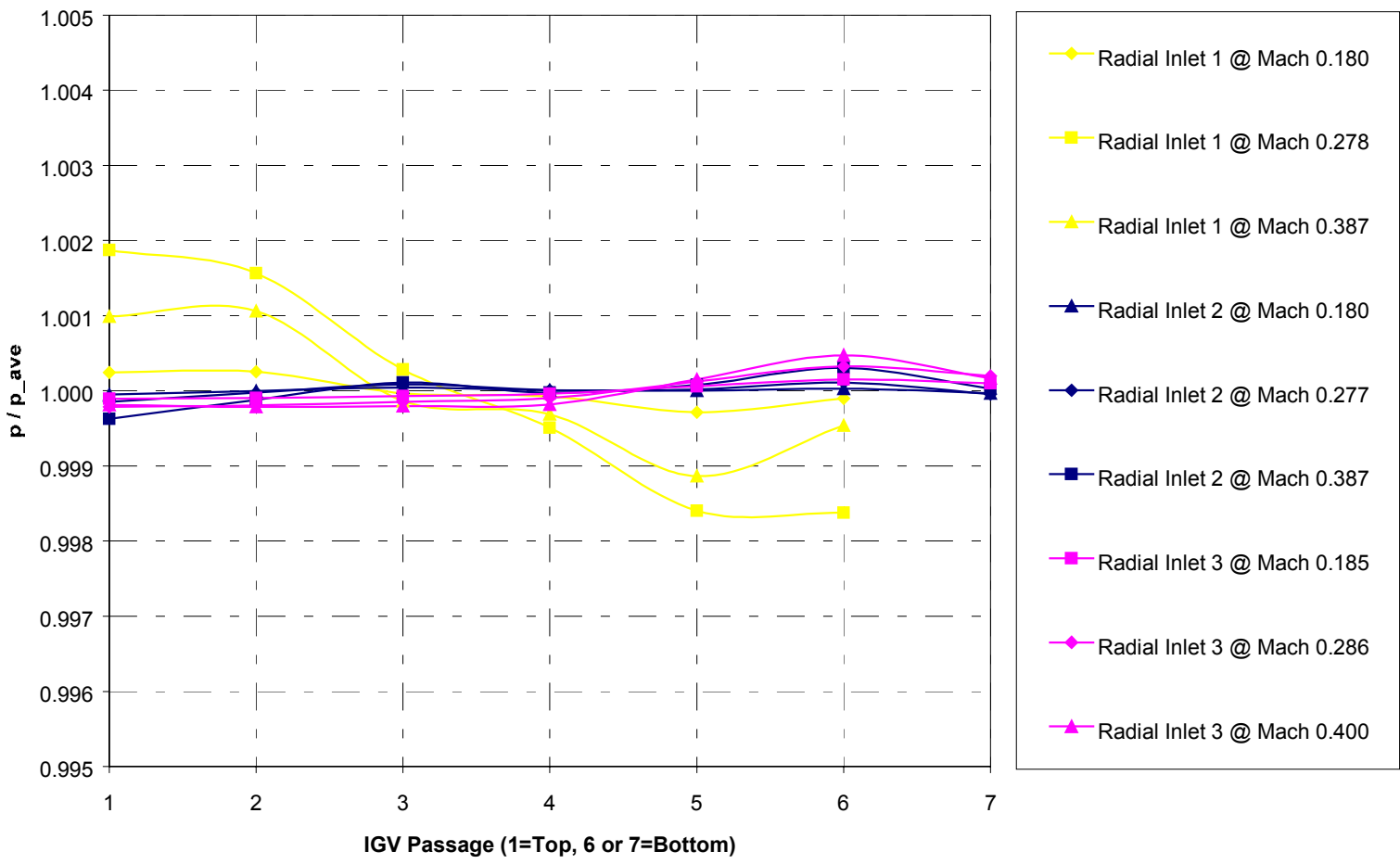

Figure 11. Normalized pressure distribution @ various exit Mach no.

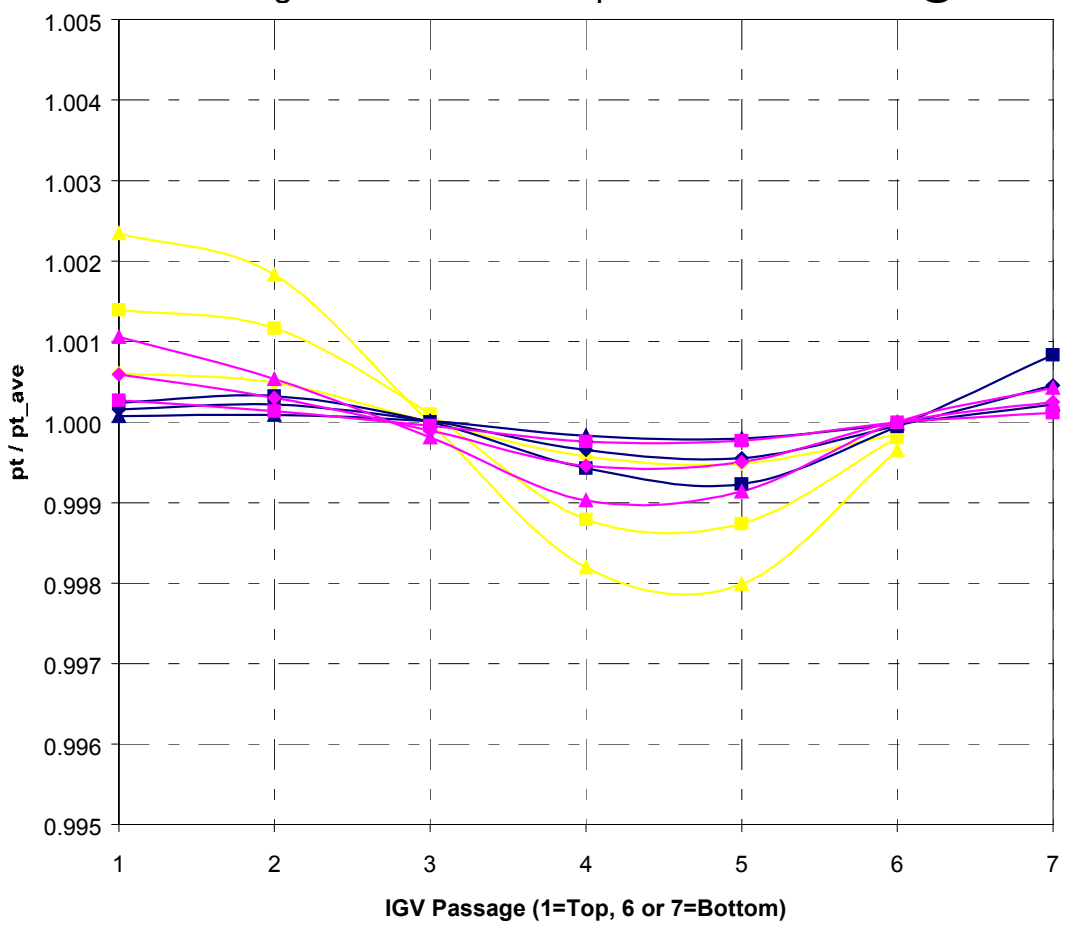

Radial Inlet 1 @ Mach 0.180

Radial Inlet $1 @$ Mach 0.278

Radial Inlet 1 @ Mach 0.387

$\_$Radial Inlet 2 @ Mach 0.180

$\multimap$ Radial Inlet 2 @ Mach 0.277

Radial Inlet 2 @ Mach 0.387

Radial Inlet 3 @ Mach 0.185

Radial Inlet 3 @ Mach 0.286

Radial Inlet 3 @ Mach 0.400

Figure 12. Normalized total pressure distribution @ various exit Mach no. 

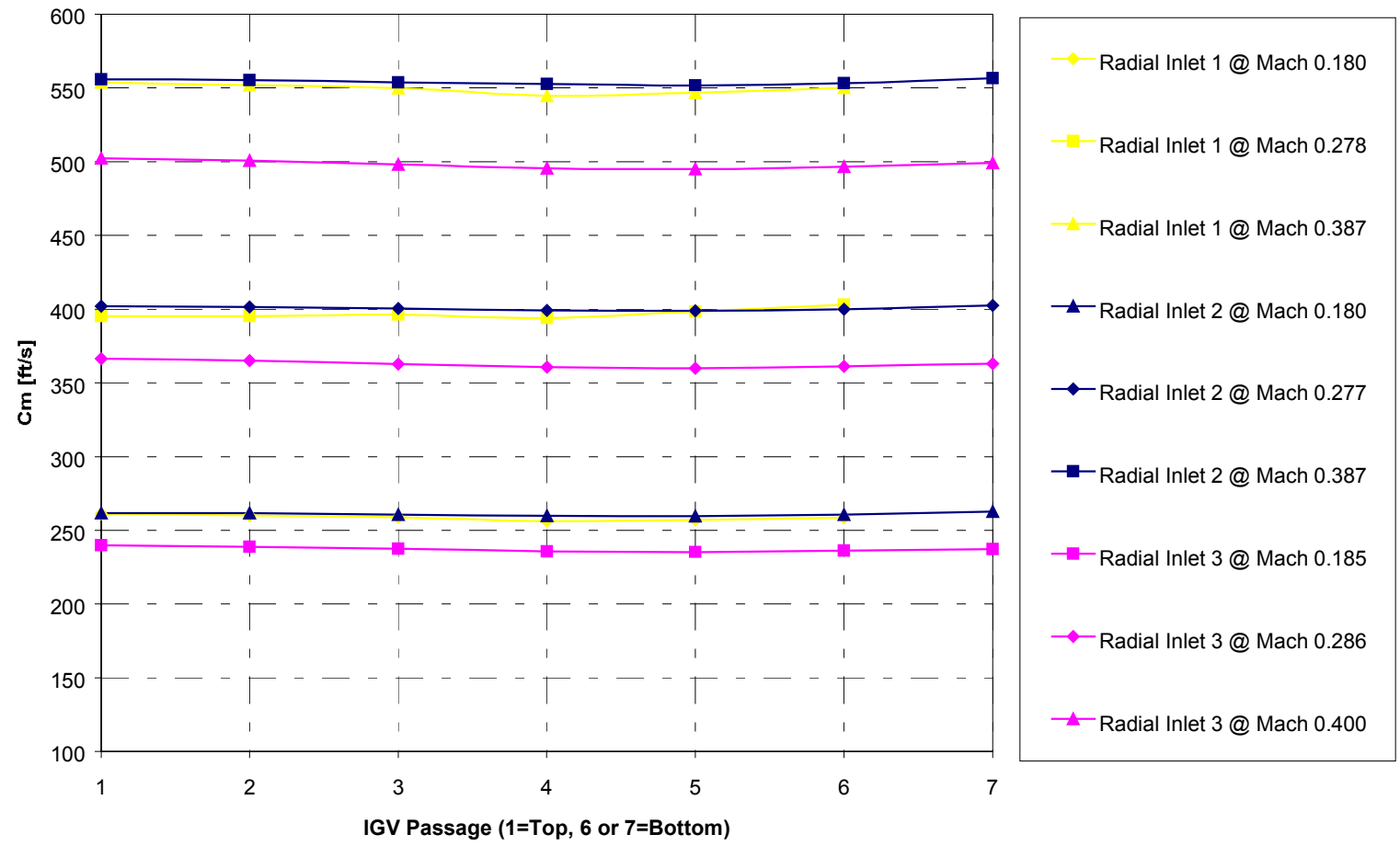

Figure 13. Meridional velocity distribution @ various exit Mach no.

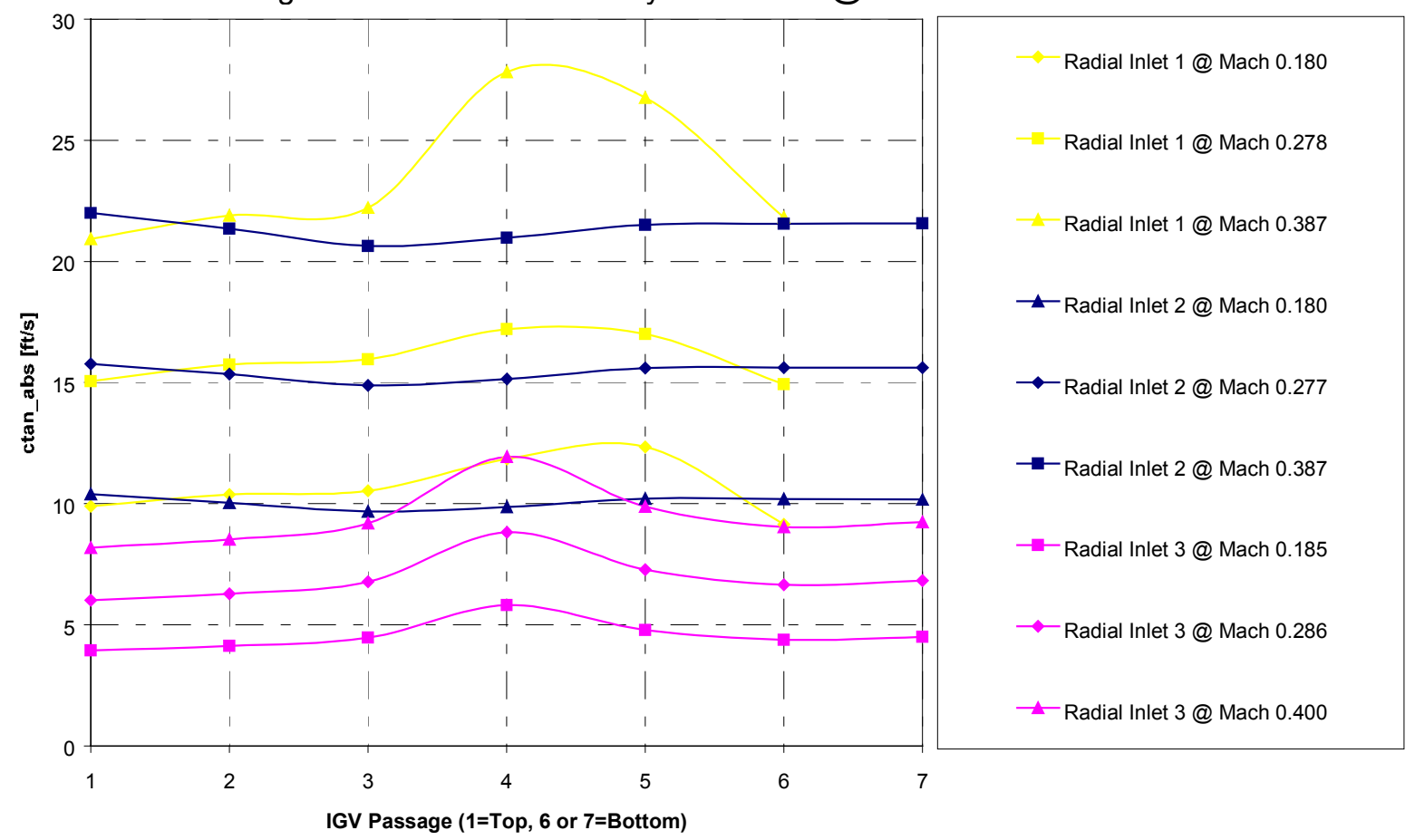

Figure 14. Absolute tangential velocity distribution @ various exit Mach no. 


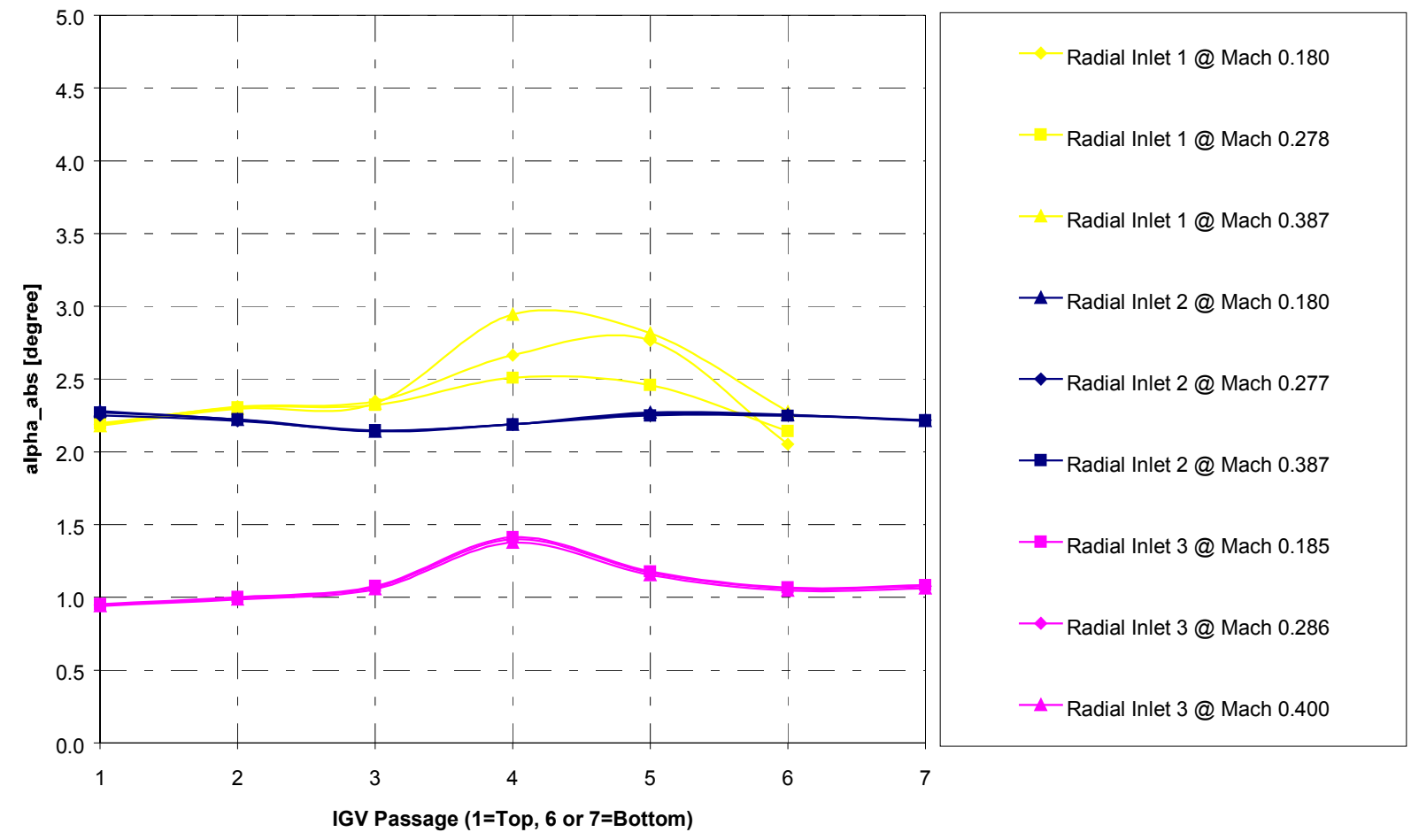

Figure 15. Absolute flow angle distribution @ various exit Mach no.
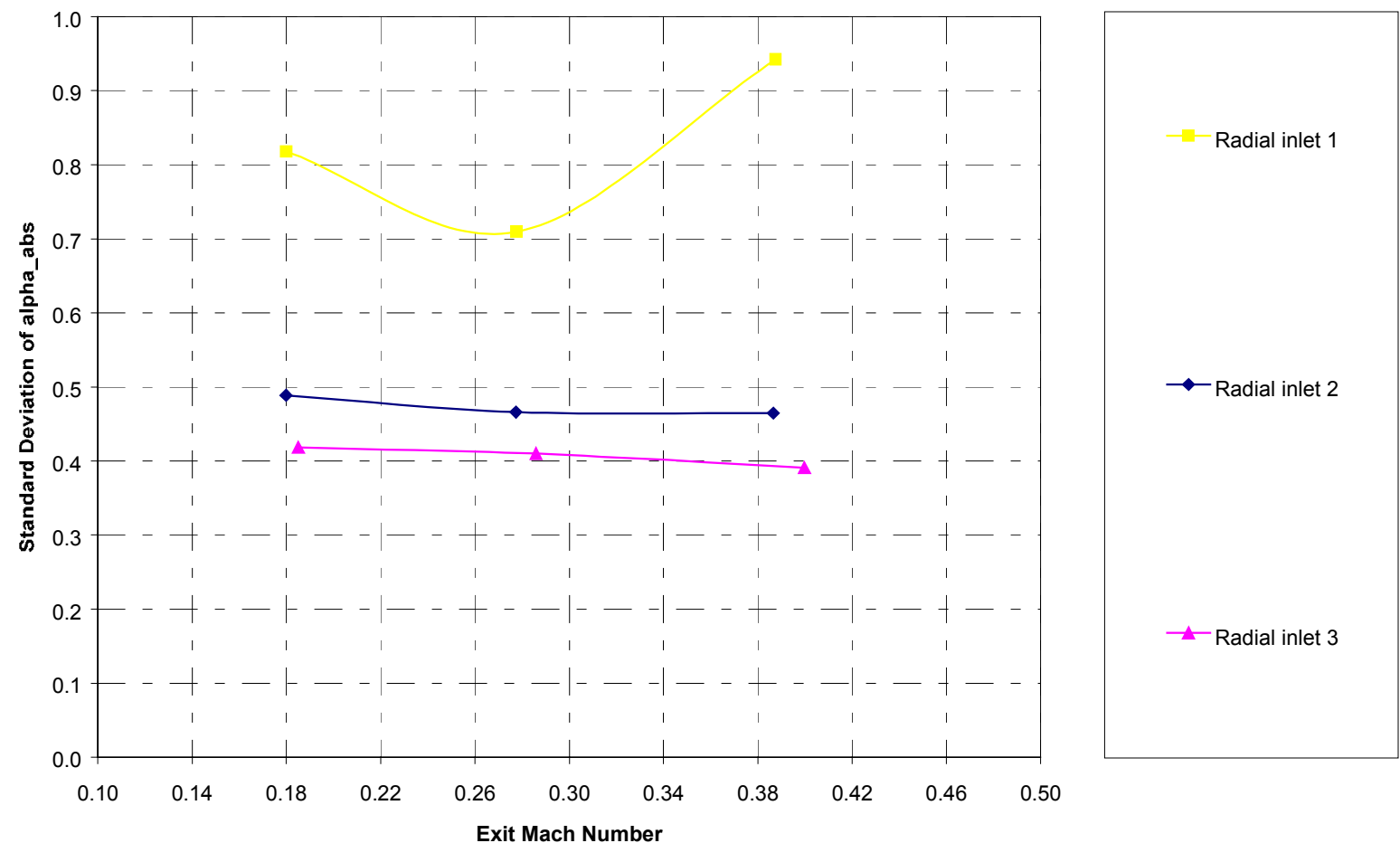

Figure 16. Standard deviation of absolute flow angle @ various exit Mach no.

Results of the aerodynamic analysis (CFD) on the final inlet configuration are as follows, 
- The third radial inlet is designed as the combination of beneficial features from the first and the second radial inlet designs on the basis of previous CFD analysis.

- The total pressure loss between the inlet flange and the exit was maintained between the third inlet design and the second inlet design.

- The mass flow, pressure, and total pressure are distributed among IGV passages approximately within $1 \%$ regardless of the exit Mach number with reference to the averaged quantities.

- Tangential velocity and flow angle of the third inlet design was further reduced from the previous designs and is less sensitive to a wide range of exit Mach numbers. This would indicate less flow distortion and improved flow uniformity at the following impeller eye.

\section{Flowpath Analysis and Design}

Several aerodynamic analyses of the compressor flowpath are being performed to evaluate the effects created by volute and diffuser geometry. These analyses are for both pie slice models and full 360degree models with the secondary passages modeled. The pie slice models were analyzed at two different speeds and three different mass flows. Several analyses of the full 360-degree models have been completed or are in process. These analyses will be completed in the next quarter. Figure 17 shows a model of the IEMDC flow passages and geometry. Both a vaneless and a vaned diffuser configuration used in these analyses are shown in Figures 18 and Figure 19. A mesh of the volute is shown in Figure 20. Figure 21 shows a pie slice model of an impeller with an axial inlet extension used in the pie slice analyses. Analyses of the full 360 degree models include the radial inlet geometry mesh as shown in Figure 21, inlet guide vane shown in Figure 22, and a full 360 degree impeller model with secondary passages as shown in Figure 23.

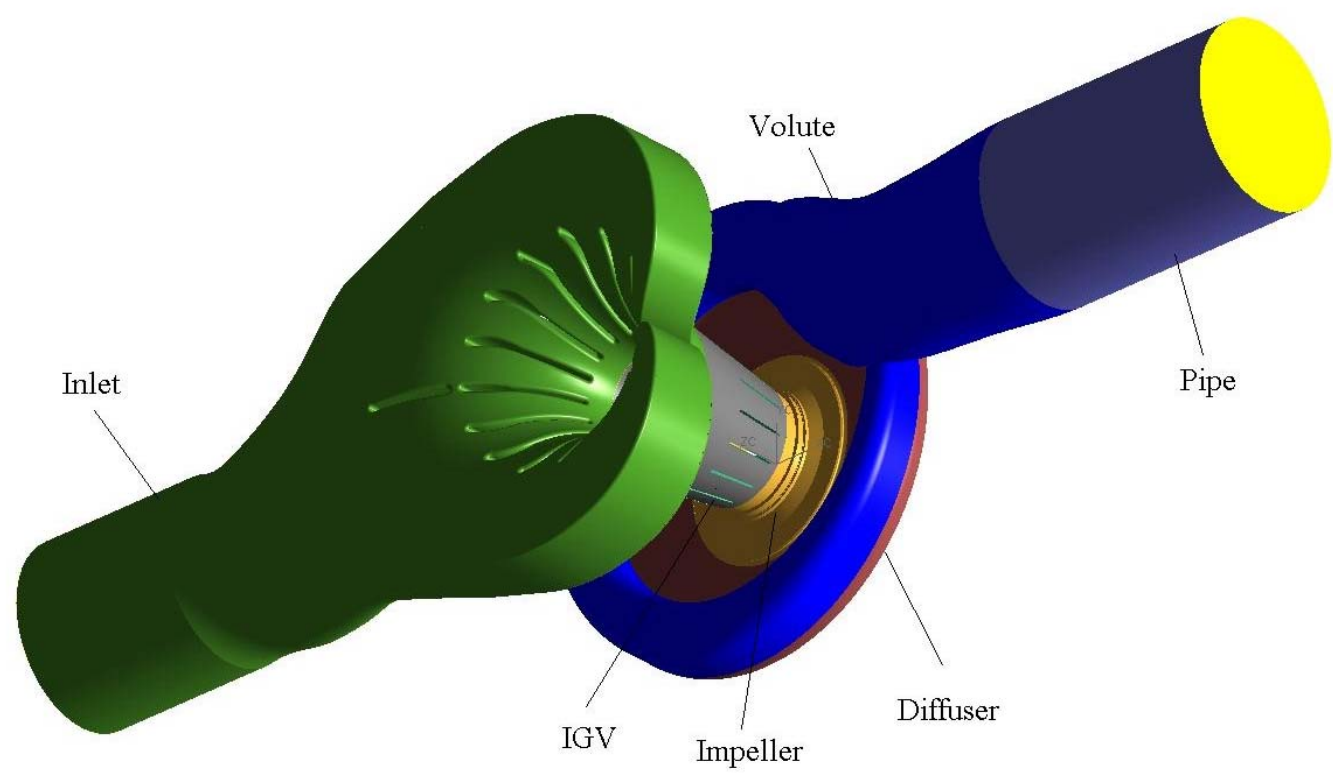

Figure 17 IEMDC compressor stage geometry 


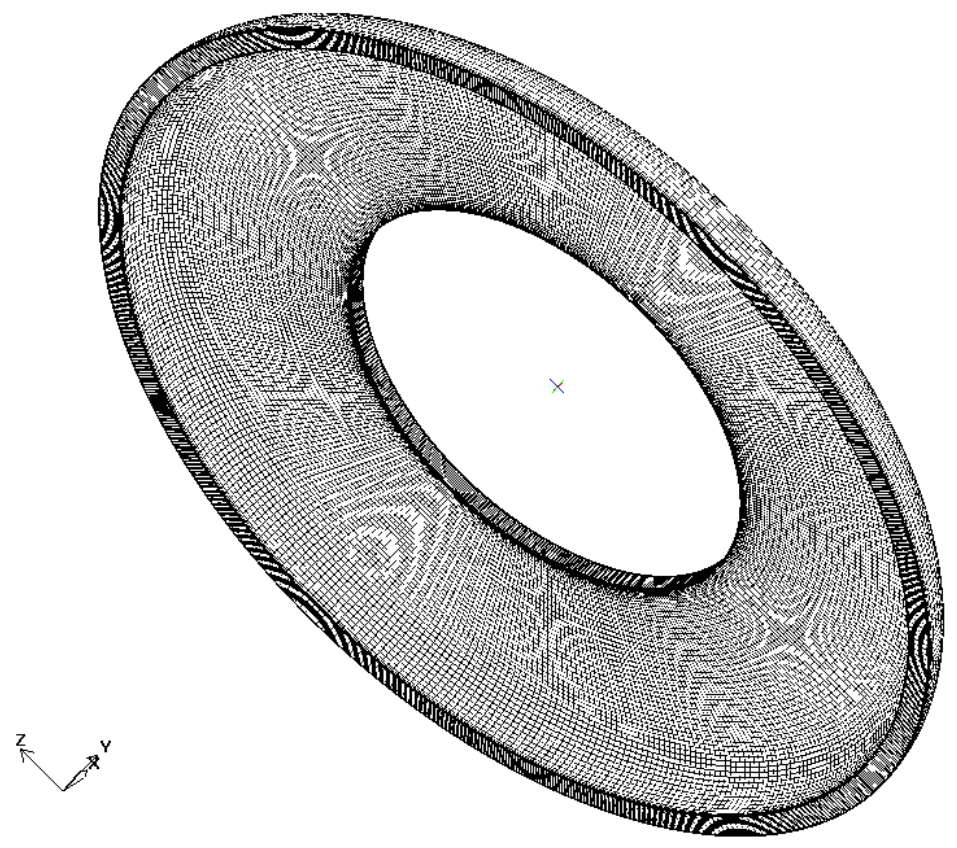

Figure 18. Vaneless diffuser computational mesh.

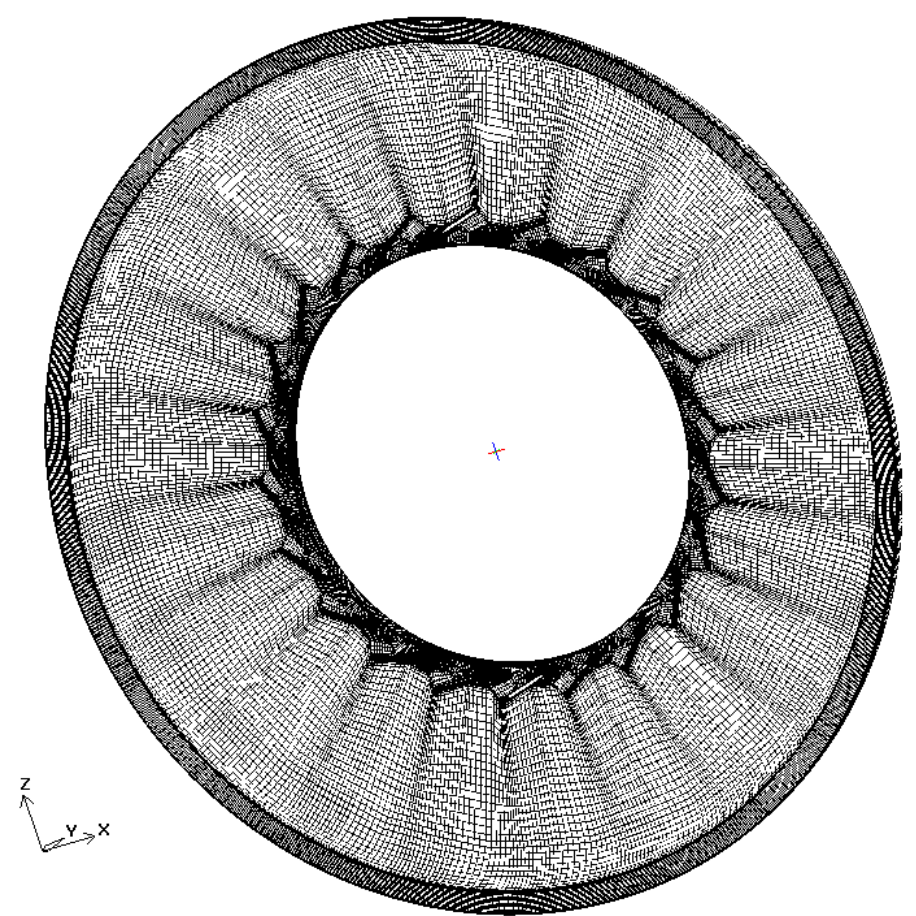

Figure 19. LSD diffuser computational mesh. 
Quarterly Progress Report - 5th Quarter

Date: April 2004

DE-FC26-02NT41643

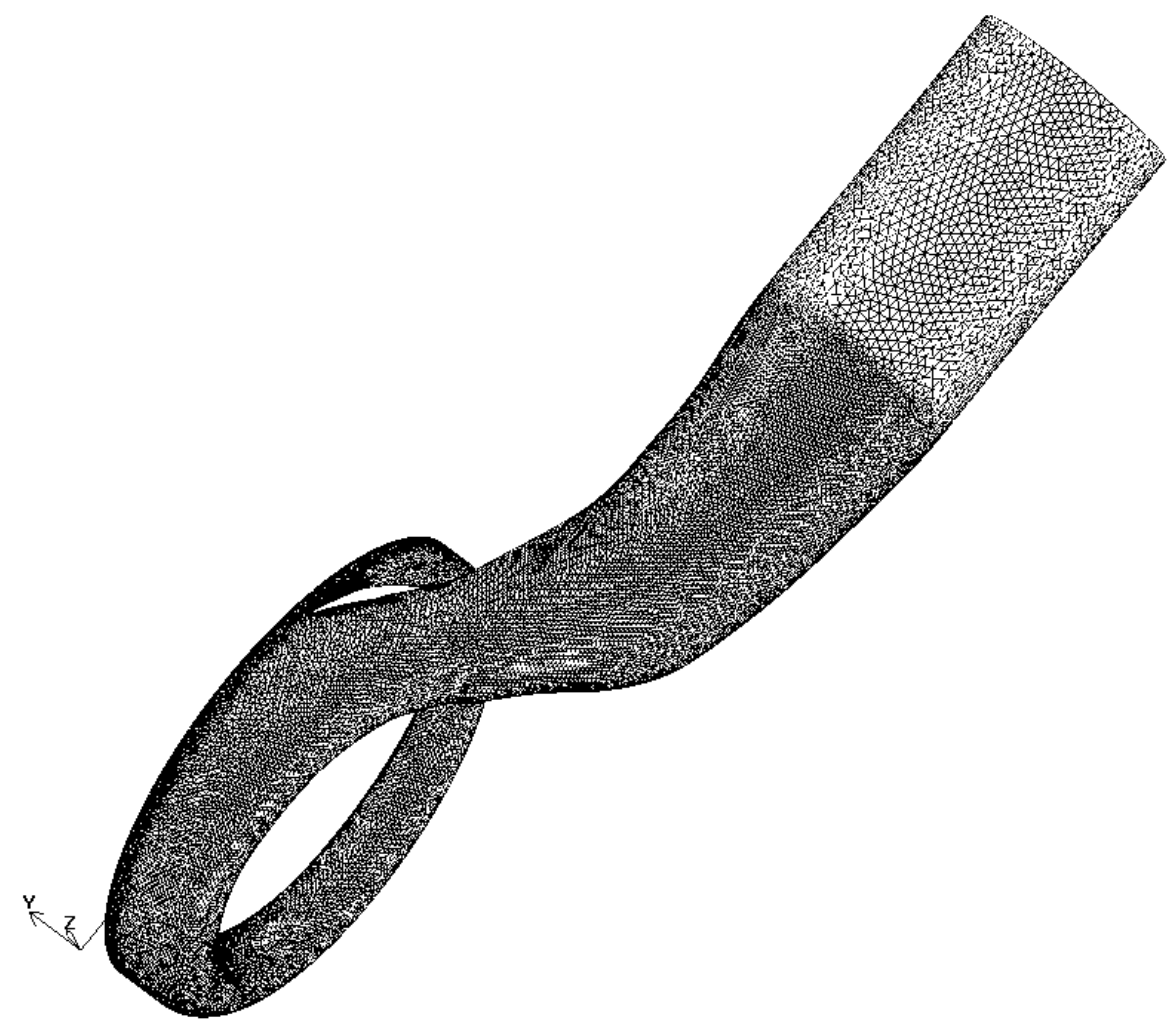

Figure 20. Volute computational mesh.

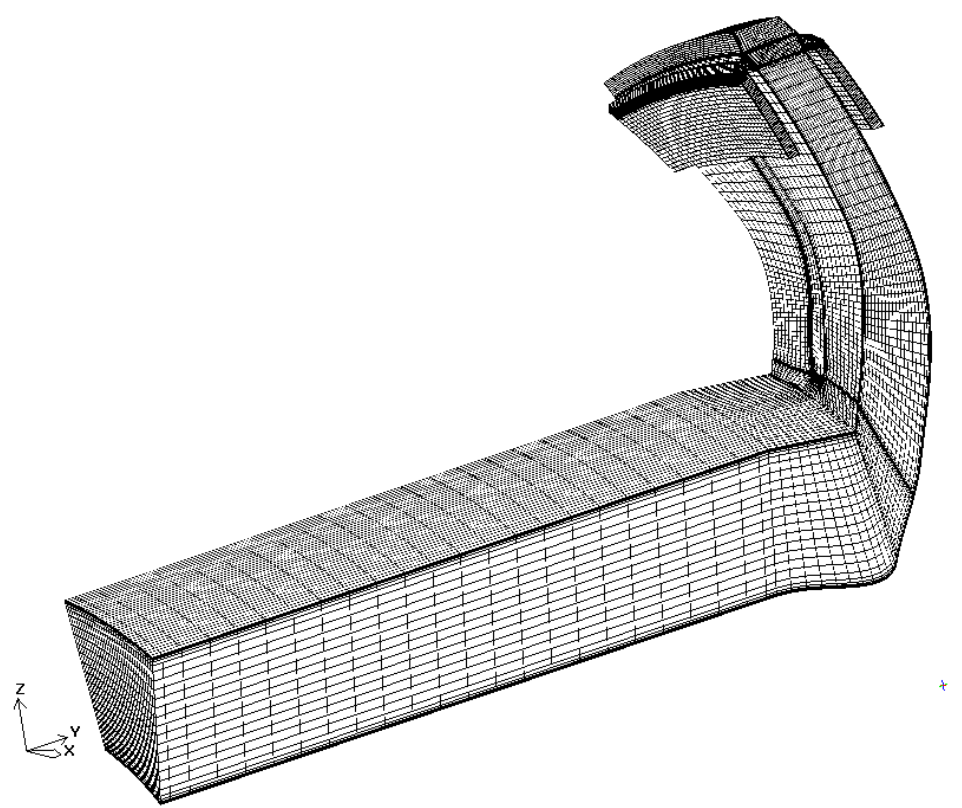

Figure 21. Pie slice impeller mesh with inlet extension. 


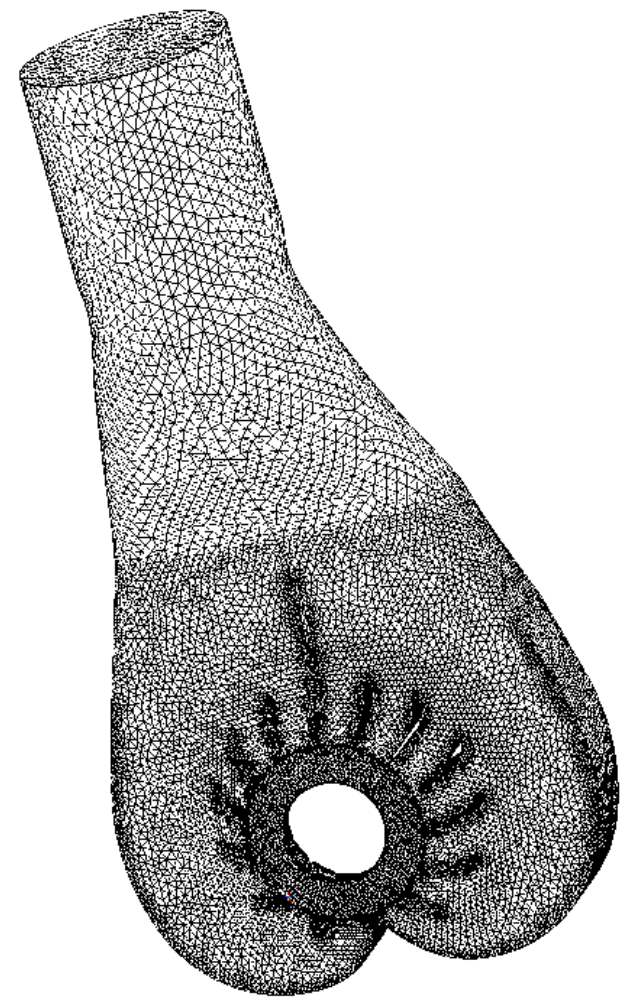

Figure 22. Inlet computational mesh.

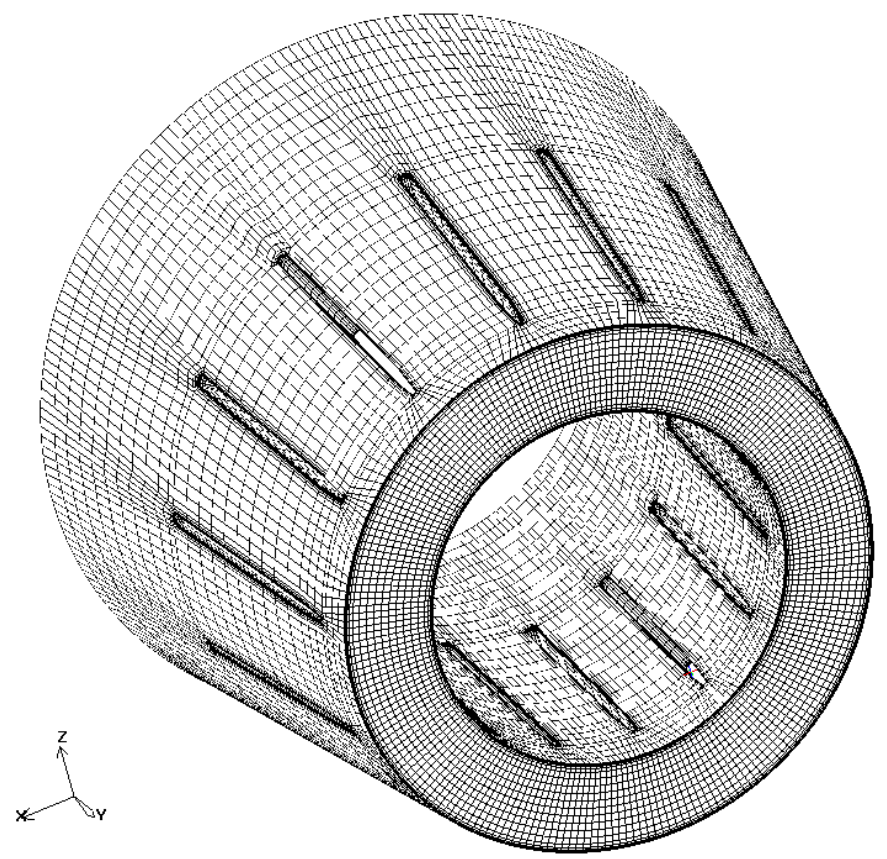

Figure 23. IGV computational mesh. 


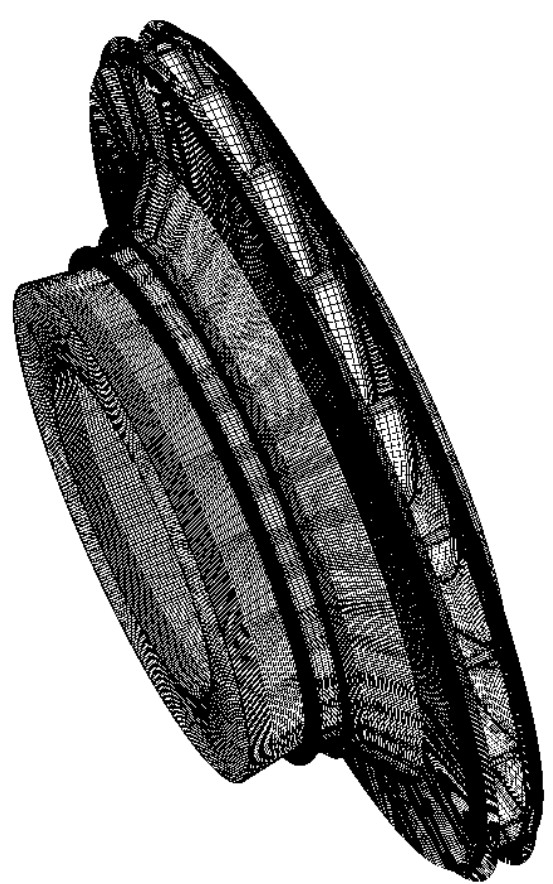

Figure 24. Full 360 impeller mesh with secondary passages.

Current results show a smooth flow field in all elements of the flowpath except at the exit cone. The exit cone shows a high rate of expansion in the transition to the discharge flange. A stream plot is shown in Figure 25 and stage pressure rise is shown in Figure 26. Figure 27 shows the pressure distribution on the impeller surface resulting from a non-axisymmetric pressure field in the volute at off-design conditions. This operating condition results in an aerodynamic radial load imparted to the impeller and subsequently the impeller end radial bearing.

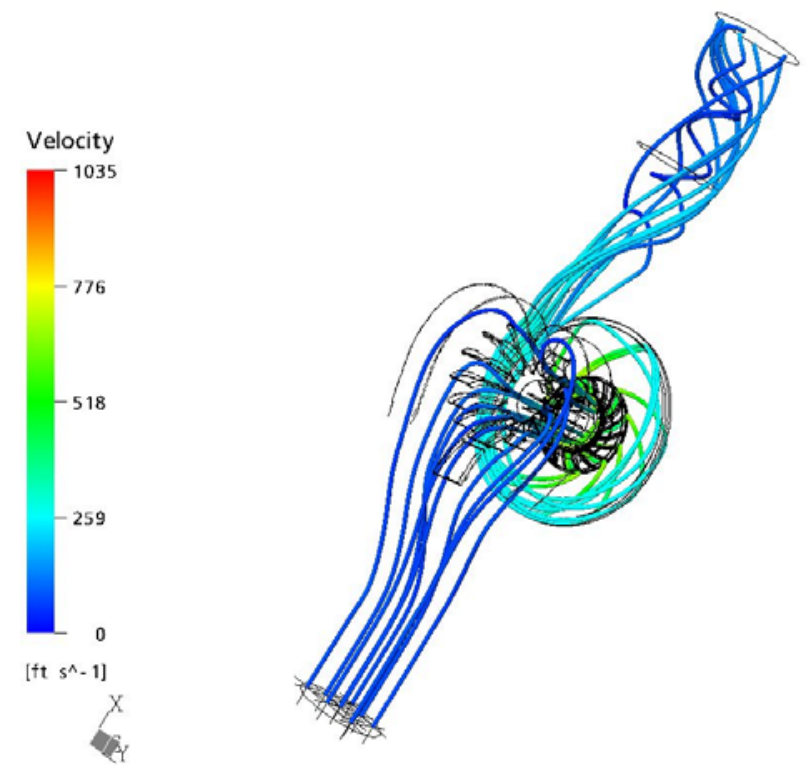

Figure 25. Streamline plot. Design flow, 11237 rpm, Stage interface. 


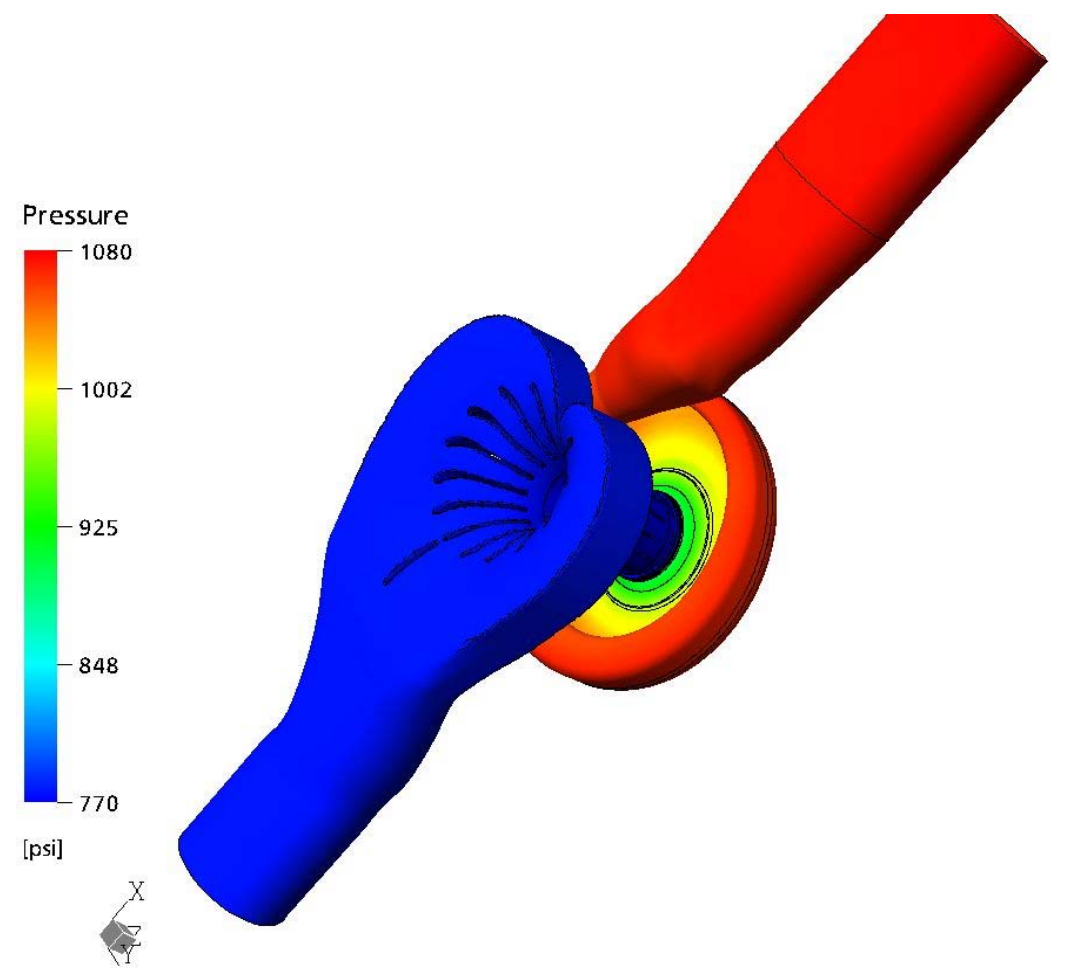

Figure 26. Pressure rise on stage walls. Design flow $11237 \mathrm{rpm}$.
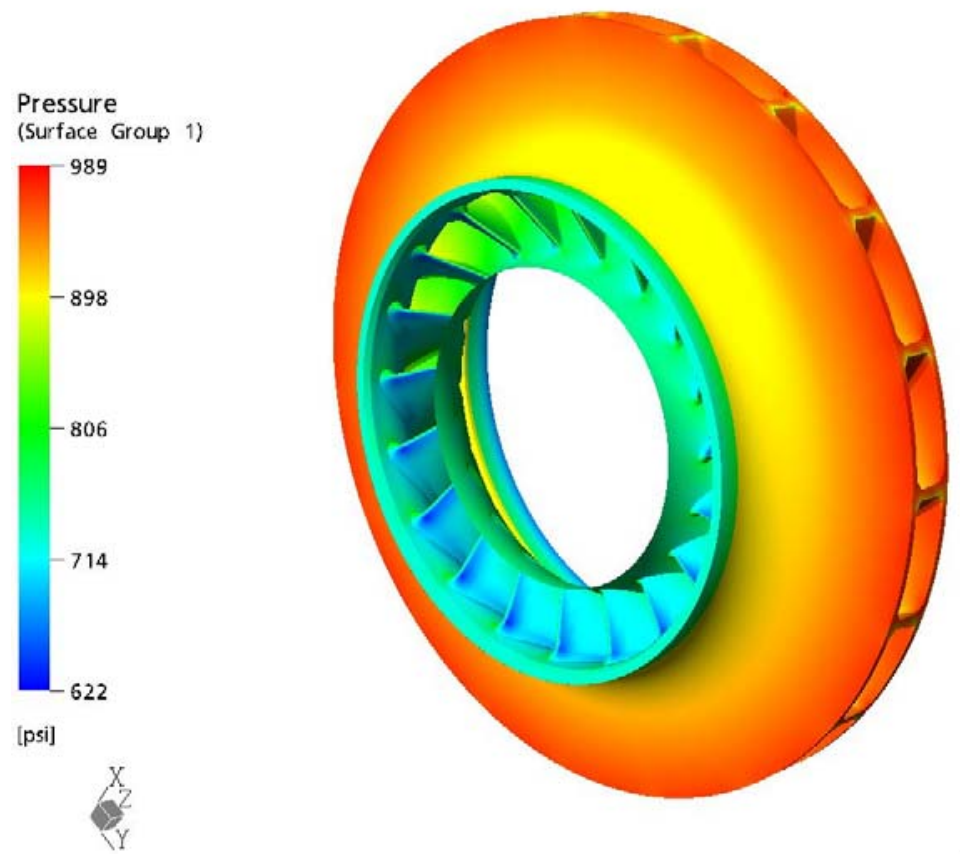

Figure 27. Non-axisymmetric pressure load on the impeller surface.

A preliminary review indicates that the aerodynamic radial loading for the vaneless diffuser is less than $2000 \mathrm{lb}_{\mathrm{f}}$ at surge. However, the introduction of vanes in the diffuser should significantly reduce the 
aerodynamic radial loads and improve peak efficiency with some reduction in the operational range. More analysis work has not been completed and more work is required develop a more accurate prediction.

\section{Unit Performance}

The operating parameters shown in Table 1 were selected as a basis for the prototype unit design point. A preliminary performance will be generated based on the below conditions and will form the basis for all related DOE deliverables.

Table 1. Prototype Design Operating Point

\begin{tabular}{|l|c|}
\hline \multicolumn{1}{|c|}{ Parameter } & \multicolumn{1}{|c|}{$\begin{array}{c}\text { IEMDC Prototype Unit } \\
\text { Design Point }\end{array}$} \\
\hline Gas Handled & Natural Gas \\
\hline MMSCFD & 613 \\
\hline Weight Flow (Ib/min-wet) & 18,990 \\
\hline \multicolumn{1}{|l|}{ Inlet Conditions } & 763 \\
\hline Pressure (psig) & 60 \\
\hline Temperature ( ${ }^{\circ}$ F) & \\
\hline \multicolumn{1}{|c|}{ ischarge Conditions } & 1100 \\
\hline Pressure (psig) & \\
\hline & 11865 \\
\hline Horsepower (BHP) & 11238 \\
\hline Speed (RPM) & \\
\hline
\end{tabular}

\section{Electric Motor Design}

\section{Magnetic Bearing Design}

The results of the magnetic bearing system design were reviewed during a joint meeting with DresserRand, Kingsbury/S2M and Curtiss-Wright EMD. The analysis results show that the design meets the requirements of the API standards 541 and 617 with respect to rotor critical speeds and the unbalance response. The radial and thrust magnetic bearings that are being used in the IEMDC motor have a proven, field tried, track record. About 60 similar design magnetic bearings have been in operation in high-pressure gas environment in a variety of turbo-machinery. Some of the bearings have been in operation for the last 15 -years. The magnetic bearing controller is fully capable of permitting the motor to operate to its max design operating speed of $12,000 \mathrm{rpm}$. The radial and thrust magnetic bearings as well as the back up bearings fit into the allocated space. Thus providing a compact motor design.

The drawing package of the magnetic bearings is being finalized. A detailed discussion of the analysis results is being prepared in a report and will be presented and discussed in the next quarterly report.

\section{Motor Pressurized Housing and Motor-Compressor Interface Flange Design}

A comprehensive design report has been prepared showing the design calculations of the motor pressurized housing and the motor-compressor interface flange designs (see Appendix A). The analysis was performed to satisfy the design requirements of API standard 617, 7th edition and Section VIII of the ASME Code, 2001 edition. The predictions of the design analysis verify that the IEMDC motor housing pressure boundary components satisfy the requirements of the ASME Code and the API 617. The 1.5 inch $900-\mathrm{lb} 316$ stainless steel welding neck flanges have a pressure rating of $1610 \mathrm{psi}$ at $350^{\circ} \mathrm{F}$. The functional 
evaluation verifies that the O-rings will remain sufficiently compressed during the shop hydro test at 2250 psi. In summary, the design meets all the code requirements and is predicted to be safe and robust. The complete report with discussion of results is included in Appendix A.

\section{Effect of "Sweet Natural Gas" Constituents on Motor Insulation System}

Extensive literature search was performed to collect, review, and to evaluate relevant information to investigate the effect of the constituents of the "sweet natural gas" on the motor insulation system. The insulation system consists of a mica glass tape, anhydride epoxy vacuum pressure impregnated. The gas constituents are described in various gas pipeline tariffs and were also obtained from a potential IEMDC end user. The preliminary findings are that no adverse impact on the motor insulation life is anticipated from the filtered high-pressure gas that will be supplied to cool the motor. The cooling gas will be introduced at the stator ends and will exit from the motor at the mid section. The results of the literature search will be summarized in a report during next quarter.

\section{Stator Half-Coil Design}

Preliminary drawings of the stator showing the half coils were prepared. Several meetings were held with the stator manufacturer to discuss the requirements of the stator half-coil design. The design effort is now underway with completion expected by end of May 2004.

\section{Design of Junction Boxes}

The electrical and mechanical design of junction boxes for the motor power leads and instrumentation cables requires investigation of several design codes. This is due to high voltage and hazardous operating environment. Copies of pertinent codes have been procured. The review of codes is now underway and the design will be completed during the next quarter. 


\section{Conclusion}

Work performed during the fifth quarter provided continued focus on the aerodynamic and mechanical design and development of the IEMDC unit. Motor design efforts focused on the design of the magnetic bearing system, motor pressure containing housing, and the motor-compressor interface flange.

Compressor effort focused on the development of component solid models, performing aerodynamic analyses on the flowpath using computational fluid dynamics, and packaging work on the gas conditioning system. These efforts show that continued progress has been made on the development of the IEMDC unit. Additionally, all efforts during this period demonstrate the feasibility of the IEMDC unit, system, and configuration.

The progress over this reporting period and the previous periods continue to show that the technical challenges of the IEMDC configuration can be overcome in addition to producing a design closer to realization. Continuous development progress on the compressor and electric motor demonstrates that the integration of the compressor and electric motor can be successfully achieved.

Furthermore, key design advantages of the IEMDC over conventional technology continue to be maintained. These advantages include several key industry attributes such as operational flexibility, remote operation and automation, efficiency, reduced maintenance issues, and environmental benefits. Magnetic bearings require no lubrication; the variable speed electric motor produces no combustion byproducts, and a sealed design does not allow process gas to leak into the atmosphere. It also maintains the capability to be installed in-line with the process piping and potentially in an underground vault.

The evolution of the integrated motor-compressor design continues to confirm the viability of the innovative IEMDC system. This is a very significant achievement. The successful development of this new advanced technology integrated motor-compressor system would provide to the Natural Gas Industry, a competitive low cost and low maintenance gas compression alternative. 


\section{References}

American Society of Mechanical Engineers, 1998, Boiler and Pressure Vessel Code, Section VIII, Division 1 and Division 2.

API Standard 617, $7^{\text {th }}$ Edition, July 2002, "Axial and Centrifugal Compressors and Expander-compressors for Petroleum, Chemical, and Gas Industry Services".

API 541, $3^{\text {rd }}$ edition, April 1995,"Form-Wound Squirrel Cage Induction Motors - 250 Horsepower and Larger". 
Quarterly Progress Report - 5th Quarter

Date: April 2004

DE-FC26-02NT41643

List of Acronyms and Abbreviations

$\begin{array}{ll}\text { AF } & \text { Amplification Factor } \\ \text { API } & \text { American Petroleum Institute } \\ \text { ASME } & \text { American Society of Mechanical Engineers } \\ \text { BPV } & \text { Boiler and Pressure Vessel Code } \\ \text { CFD } & \text { Computational Fluid Dynamics } \\ \text { c.g. } & \text { Center-of -Gravity } \\ \text { DR } & \text { Dresser-Rand Company } \\ \text { EMD } & \text { Curtiss-Wright Electro-Mechanical Corporation (EMD) } \\ \text { F } & \text { Fahrenheit } \\ \text { FEA } & \text { Finite Element Analysis } \\ \text { GMRC } & \text { Gas Machinery Research Council } \\ \text { Hp } & \text { Horsepower } \\ \text { Hz } & \text { Hertz } \\ \text { IEMDC } & \text { In-Line Electric Motor Driven Compressor } \\ \text { IGV } & \text { Inlet guide vane } \\ \text { I/O } & \text { Input / Output } \\ \text { kV } & \text { kilovolt } \\ \text { kW } & \text { kilowatt } \\ \text { kWh } & \text { Kilowatt hour } \\ \text { Lb } & \text { pound } \\ \text { Log Dec } & \text { Logarithmic Decrement } \\ \text { Mil } & \text { one one-thousands of an inch } \\ \text { MW } & \text { megawatt } \\ \text { PSI } & \text { Pounds per square inch } \\ \text { RFQ } & \text { Request for Quotation } \\ \text { RPM } & \text { Revolutions per minute } \\ \text { RTD } & \text { Resistance Temperature Detector } \\ \text { THD } & \text { Total Harmonic Distortion } \\ \text { V } & \text { Volts } \\ \text { VFD } & \text { Variable Frequency Drive } \\ & \end{array}$

